\title{
EL VALOR INTRÍNSECO DE TODA VIDA HUMANA
}

\author{
Prof. Ezequiel Piro
}

Hace mucho tiempo, un entrañable amigo me comentó emocionado lo que, a su modo de entender, había sido una clara victoria en un intercambio de argumentos acerca del aborto. Me dijo que una persona que se autodenominaba "defensora de la vida" había utilizado para sostener su posición el siguiente planteo: si sus madres hubieran hecho los respectivos abortos, no hubieran nacido Beethoven, Einstein y tantas otras personas que se destacaron en distintos ámbitos. Mi amigo, rápido de reflejos, contestó que tampoco hubiesen vivido Hitler, Stalin y otros numerosos seres humanos que provocaron grandes daños a la humanidad.

Al comentar esta situación con algunos alumnos, estos quedaron algo perplejos y asumieron que ambos puntos de vista eran razonables. Un empate técnico. Inmediatamente, cuando me puse a analizar los argumentos puse el acento en que, en realidad, ambos adolecían del mismo defecto. El valor que le daban a la vida estaba ligado a los resultados que sus poseedores obtenían a partir de sus acciones. Beethoven y Einstein, indudablemente, "cotizaban alto", en cambio, los otros, "daban pérdida".

Acostumbrados como estamos a valorar casi completamente todo desde el punto de vista exclusivamente económico, con un cálculo de la relación costo-beneficio, se nos suele pasar por alto que hay muchas cosas que no pueden ser comparadas entre sí porque pertenecen a categorías distintas. Por ejemplo, carecería de sentido preguntarse si es mejor el color azul o el número doce.

Una vida humana no vale por lo que su portador produce ni por las acciones que éste lleva a cabo, sean dignas de admiración o, contrariamente, despreciables. Una vida humana vale porque, valga la redundancia, es humana. La ciencia lo ha dejado claramente probado hace tiempo: hay vida humana desde el momento de la fecundación. La Dra. Laura María Vargas Roig, en su magistral exposición ante las Comisiones de Legislación General, Legislación Penal, Acción Social y Salud Pública y Familia, Mujer, Niñez y Adolescencia de la 
Cámara de Diputados de la Nación Argentina, confirma que "a partir del proceso de fecundación, el nuevo ser adquiere su identidad biológica como individuo concreto porque posee no solamente un genoma propio, que es más que la suma del genoma materno y paterno, sino que también posee la capacidad de expresar dicho genoma.." ${ }^{11}$ La investigadora del Consejo Nacional de Investigaciones Científicas y Técnicas (CONICET) destaca que "a partir de la fecundación estamos en presencia de un organismo individual lo cual no ha podido ser rebatido por algunos modelos propuestos como por ejemplo el de gemelación monocigótica."

El Nuevo Código Civil y Comercial se hace eco de este dato científico que no hace más que corroborar el histórico común sentir de la humanidad- y dice en el artículo 19 que "la existencia de la persona humana comienza con la concepción."

Sin necesidad de adentrarnos en la cuestión acerca de cuándo es persona el ser humano, hay algo que, por lo dicho, no se puede poner en duda: que es un ser humano siempre. Por eso es importante centrarse en este punto al momento de debatir la cuestión del aborto. Si es un ser humano desde el inicio, si asumimos que la vida humana tiene valor independientemente de los efectos y resultados que produzca, entonces el aborto no puede ser la solución de nada, porque lo que hace es eliminar deliberadamente una vida humana que, además, es absolutamente inocente.

En la Exhortación apostólica Evangelii Gaudium, el Santo Padre Francisco afirma que "esta defensa de la vida por nacer está íntimamente ligada a la defensa de cualquier derecho humano. Supone la convicción de que un ser humano es siempre sagrado e inviolable, en cualquier situación y en cada etapa de su desarrollo. Es un fin en sí mismo y nunca un medio para resolver otras dificultades." ( $n^{\circ}$ 213) Por eso, el Sumo Pontífice profundiza en esa línea argumental remarcando que, si dicha "convicción se viene abajo, no quedan fundamentos sólidos y permanentes para defender los derechos humanos, que siempre estarán sometidos a conveniencias circunstanciales de los poderosos de turno." ( $n^{\circ} 213$ ) Esto no es una advertencia de cara al futuro. Se trata de la constatación de un hecho reiterado en distintos momentos de la historia y en diferentes lugares del planeta.

Ahora bien, todo lo que afirmamos no significa que no haya que buscar soluciones a los problemas que se les presentan a tantas mujeres embarazadas, más bien, quiere decir no agregar problemas a los que ya tienen o creen tener. Muchas veces las complicaciones que les aparecen en el camino radican más en la falta de alternativas visibles que en la misma situación que les toca vivir. En

\footnotetext{
${ }^{1}$ Exposición de Laura María Vargas Roig en la reunión informativa del 10 de mayo de 2018 sobre los proyectos de ley de legalización del aborto en debate ante las Comisiones de Legislación General, Legislación Penal, Acción Social y Salud Pública y Familia, Mujer, Niñez y Adolescencia de la Cámara de Diputados de la Nación Argentina.
} 




este sentido, provocar deliberadamente la muerte de alguien no puede ser - hoy mucho menos que antes- la manera de resolver las dificultades que surgen en el itinerario vital de tantas personas. $Y$ no se trata de negar que, en muchas ocasiones, los inconvenientes son reales y complejos, y que el peso que generan es muy difícil de cargar sin una ayuda proporcionada. Pero como sociedad que quiere crecer y madurar, tenemos que encontrar respuestas creativas y generosas si realmente queremos vivir en armonía y en paz. Una sociedad que presenta como el triunfo del derecho de algunos seres humanos la eliminación de otros seres humanos inocentes e indefensos, no se puede decir que, como sociedad, manifieste demasiado crecimiento integral ni desarrollo. No se puede aceptar como regla la eliminación de un ser humano porque no se lo desea, porque no cumple con los "requisitos" anatómicos, genéticos, porque incomoda o por cualquier razón que se pueda esgrimir. Toda vida humana es valiosa en sí misma.

Llegamos así al principio que es la piedra angular de toda la cuestión: el valor intrínseco de toda vida humana - querida especialmente por Dios desde toda la eternidad - es el fundamento de la obligatoriedad de defender dicha vida ante cualquier situación de injusticia o peligro.

\section{Bibliografía}

Francisco. (2013). Evangelii Gaudium. Ciudad del Vaticano. 